\title{
Superbases for organic synthesis
}

\author{
Manfred Schlosser \\ Institut de Chimie Organique de l'Université \\ Rue de la Barre 2, CH-1018 Lausanne (Switzerland)
}

\begin{abstract}
LICKOR" mixtures of organolithium reagents and bulky potassium alcoholates allow the smooth metalation and subsequent electrophilic substitution of low acidity hydrocarbons, in particular olefins. The allylpotassium intermediates exhibit peculiar conformational preferences which can be exploited in novel stereoselective carbon-carbon linking reactions. A few syntheses of simple natural products illustrate the method. A tentative explanation is given for the superior performance of LICKOR mixtures when compared with butylpotassium.
\end{abstract}

\section{INTRODUCTION}

The generation of reactive allylmetal species by proton abstraction from simple olefins using organosodium or organopotassium compounds was extensively studied by A.A. Morton and his associates (ref. 1). Their methods, however, never became very popular since they required special equipment, high-speed stirring and long reaction times. Moreover, despite a huge excess of the hydrocarbon substrate, frequently only unsatisfactory yields were obtained. Thus, it was an encouraging achievement when activation by $N, N, N, N^{\prime}$-tetramethylethylenediamine (ref. 2 ) was found to be strong enough to enable butyllithium or tert-butyllithium to metalate the most reactive olefins such as isobutene (ref. 3) and 1- or 2-butene (ref. 4). Shortly afterwards the superbasic properties of $1: 1$ mixtures of alkyllithium ("LIC") and potassium alcoholates ("KOR") were recognized (ref. 5). When applied to the metalation of straight-chain and branched olefins (ref. 6) the "LICKOR superbase" exhibited an unprecedented reactivity and, at the same time, selectivity profile. The reaction was perfectly typoselective : unlike isopropyllithium and tert-butyllithium which add to the double bond of simple alkenes such as propene (ref. 7), butyllithium in the presence of potassium tert-butoxide only promotes a hydrogen/metal exchange. The proton abstraction is highly regioselective : allylic methyl groups are much more readily attacked than such methylene groups, let alone methine centers. Finally, a stereoselective behavior was encountered : cis-2-alkenes generally react faster than their trans-isomers. This holds even for the 4,4-dimethyl-2-butenes where the trans-isomer leads to the thermodynamically favored product (ref. 8).

\section{METAL-MEDIATED FEATURES OF ALLYL-TYPE ORGANOMETALLICS}

Treatment of isobutene with butyllithium and potassium tert-butoxide mainly produces isobutenylpotassium and lithium tert-butoxide. Thc latter component can be removed by extraction (ref. 6).

A first question arises now regarding the structure of alkenylpotassium compounds. By studying the effect of methyl and deuterium substituents on ${ }^{13} \mathrm{C}$ chemical shifts we were able to confirm the presumed (ref. 9) $\sigma$-bonded $\left(\eta^{1}\right)$ structure of allyl-type Grignard reagents (e.g. 1) (ref. 10). On the other hand, a symmetrical $\pi$-complex $\left(\eta^{3}\right)$ structure was found for allylpotassium (3) and allylcaesium (ref. 10), while the spectra of allyllithium (2) and allylsodium (ref. 11) were interpreted on the basis of slightly asymmetric, though basically still trihapto $\left(\eta^{3}\right)$ interactions (ref. 10,12).
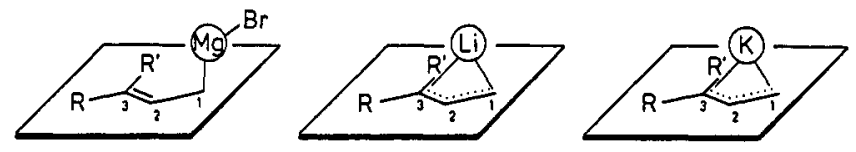

Regardless of their ground state geometry, allylmetal compounds have highly fluxional structures. We differentiate three distinct modes of metal mobility : (a) intermolecular exchange; (b) reversible transitions between $\sigma$ - and $\pi$-bonded species which at the same time provides a mechanism for the metallotropic conversion of $\sigma$-structures into their mirror images; (c) torsional motion by which process the metal can move from the upper to the lower face, or vice-versa, in $\sigma$-bonded allyl derivatives while simultaneously the substituents at the inward ("endo") and outward ("exo") position of the rotating center change places. A combination of the two latter 
processes allows the stereomutation of crotyl- or other 2-alkenyl-type organo(earth)alkali intermediates. Endoand exo-isomers (endo- and exo-4) can interconvert by simple rotation as soon as the metal has been linked to the "inner", secondary terminus of the allyl moiety in a $\eta^{1}$-fashion (metallomer 5) and the resonance interaction between this organometallic and the olefinic $\pi$-bond has been lifted.

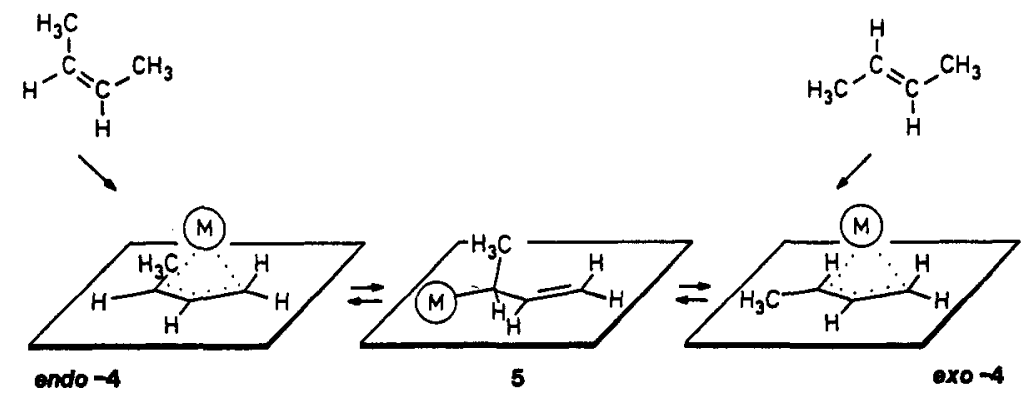

Torsional isomerism is very fast with allylmagnesium and -lithium compounds $\left[\mathrm{E}_{\mathrm{a}} \approx 10 \mathrm{kcal} / \mathrm{mol}\right.$ (ref. 13)]. In contrast, it takes many hours for most allyl-type potassium compounds $\left[\mathrm{E}_{\mathrm{a}} \geq 20 \mathrm{kcal} / \mathrm{mol}\right]$ unless it is catalyzed with magnesium (ref. 14), lithium (ref. 14) or mercury (ref. 15) derivatives. The striking difference in rates is paralleled by a similar one as far as the endo/exo-equilibrium positions are concerned. While in general magnesium and lithium intermediates do not much discriminate between the two stereoisomers, allyl-type sodium, potassium and caesium compounds increasingly favor the endo [or (Z)-] form at the expense of the sterically less hindered exo- [or $(E)$-] form (ref. 16, 17) [see table 1]. The effect which may be attributed to a special kind of intramolecular hydrogen bond (ref. 17) is particularly pronounced for straight-chain 2-alkenylpotassium compounds and notably butenylpotassium.

Table 1. (Earth)Alkali derivatives 4 of the 2-alkenyl type under equilibrium conditions in tetrahydrofuran at $-50^{\circ} \mathrm{C}:$ endo/exo-ratios ${ }^{\text {a) }}$.

\begin{tabular}{|c|c|c|c|c|c|c|}
\hline $\mathbf{R}$ & $M=H^{b)}$ & $M=M g B r$ & $M=L i$ & $\mathrm{M}=\mathrm{Na}$ & $\mathbf{M}=\mathbf{K}$ & $M=C s$ \\
\hline $\mathrm{H}_{3} \mathrm{C}$ & $1: 5$ & $1: 1$ & $3: 1$ & $10: 1$ & $100: 1$ & $1000: 1$ \\
\hline $\mathrm{H}_{3} \mathrm{C}-\mathrm{CH}_{2}{ }^{\mathrm{c})}$ & $1: 5$ & - & - & - & $20: 1$ & - \\
\hline$\left.\left(\mathrm{H}_{3} \mathrm{C}\right)_{2} \mathrm{CH}^{\mathrm{d}}\right)$ & $1: 5$ & - & - & - & $5: 1$ & - \\
\hline$\left.\left(\mathrm{H}_{3} \mathrm{C}\right)_{3} \mathrm{C}^{e}\right)$ & $1: 10^{\prime} 000^{f)}$ & - & - & - & $1: 10$ & - \\
\hline
\end{tabular}

a) All numbers rounded off; for exact values see lit. (ref. 17).

b) This column refers to the corresponding olefins (2-butene, 2-pentene, etc.).

c) Or other primary alkyl groups.

d) Or other secondary alkyl groups.

e) Or other tertiary alkyl groups. Regarding $\mathrm{R}=\left(\mathrm{H}_{5} \mathrm{C}_{6}\right)_{3} \mathrm{C}$, however, see lit. (ref. 16).

f) Estimated from differences in the heats of hydrogenation between cis- and trans-4,4-dimethyl-2pentene.

The endo/exo-ratios of the organometallic intermediates 4 can be determined by nmr spectroscopy or, often more reliably, by gas chromatography after quenching. The latter method, of course, implies the availability of an appropriate electrophile which intercepts the intermediates $\mathbf{4}$ faster than these undergo torsional isomerization. Moreover, it should get attached predominantly, if not exclusively, to the unsubstituted terminus of the allyl moiety, since only the straight-chain derivatives 6 , but not the branched regioisomers 7 , have preserved the stereochemical information.

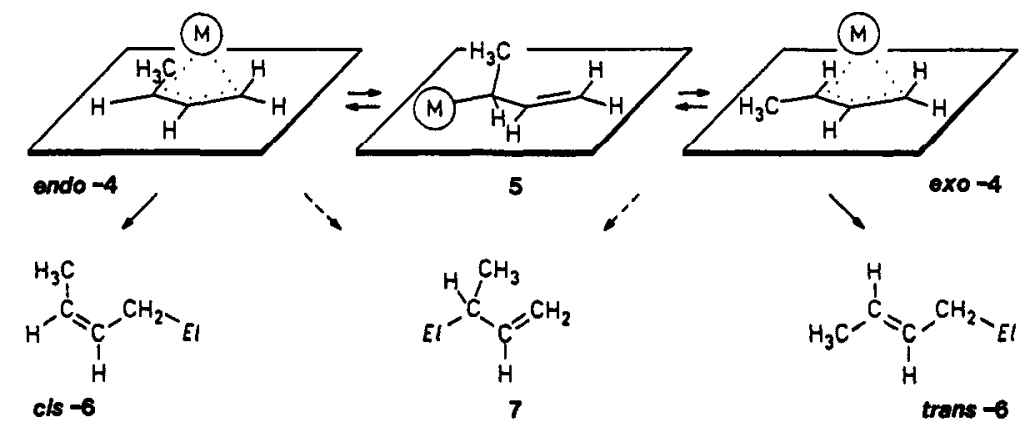

Chlorotrimethylsilane and fluorodimethoxyborane (ref. 18) satisfy best such requirements [see table 2 (ref. 19)]. In general terms organoalkali, notably organopotassium compounds of the allyl-type clearly favor the formation of chain-lengthened, primary derivatives 6 while 2-alkenylmagnesium compounds prefer to combine with electrophiles under allyl shift to vinyl substituted secondary or tertiary products 7 . 
Table 2. Reaction of 2-alkenyl- a, b) and 3-methyl-2-alkenylmagnesium bromides ${ }^{\text {a) }}$ or the corresponding organopotassium compounds $\mathrm{a}, \mathrm{b}$ ) with a variety of electrophiles $E l$-X in tetrahydrofuran at $-75^{\circ} \mathrm{C}^{\mathrm{c})}$ : ratios ${ }^{\mathrm{d})}$ of attack at the allylic 3- vs 1-position (ref. 19).

\begin{tabular}{|c|c|c|c|c|}
\hline$E I-X$ & $\mathrm{MgBr}$ & $\begin{array}{l}\mathrm{R} . \mathrm{K} \\
\therefore \vdots\end{array}$ & $\overbrace{3}^{R^{\prime}} \int_{1}^{M g B r}$ & $\begin{array}{l}\mathbf{R}^{\prime} \mathrm{K} \\
\mathrm{I}:\end{array}$ \\
\hline $\mathrm{Cl}-\mathrm{Si}\left(\mathrm{CH}_{3}\right)_{3}$ & - & $<5: 95$ & - & $0: 100$ \\
\hline $\mathrm{F}-\mathrm{B}\left(\mathrm{OCH}_{3}\right)_{2}{ }^{\mathrm{e})}$ & $90: 10$ & $<5: 95$ & $80: 20$ & $<5: 95$ \\
\hline $\mathrm{I}-\mathrm{CH}_{3}$ & $65: 35$ & $15: 85$ & $90: 10$ & $5: 95$ \\
\hline $\mathrm{I}-\mathrm{C}_{3} \mathrm{H}_{7}$ & - & $20: 80$ & $70: 30$ & $10: 90$ \\
\hline $\mathrm{Br}-\mathrm{CH}_{2} \cdot \mathrm{CH}=\mathrm{CH}_{2}$ & $65: 35$ & - & $70: 30$ & $20: 80$ \\
\hline $\mathrm{O}\left(\mathrm{CH}_{2}\right)_{2} \mathrm{f}$ & $<95: 5$ & $35: 65$ & $<95: 5$ & $20: 80$ \\
\hline $\mathrm{O}=\mathrm{CH}_{2}$ & $<95: 5$ & $35: 65$ & - & $30: 70$ \\
\hline $\mathrm{O}=\mathrm{C}=\mathrm{O}$ & $<95: 5$ & $30: 70$ & $95: 5$ & $<5: 95$ \\
\hline $\mathrm{H}_{2} \mathrm{C}=\mathrm{CH}_{2}$ & - & $85: 15$ & - & $100: 0$ \\
\hline
\end{tabular}

a) Systematic studies were carried out with 2-butenyl ("crotyl", $\left.R=\mathrm{H}_{3} \mathrm{C}\right)$, 2-hexenyl $\left(\mathrm{R}=\mathrm{H}_{7} \mathrm{C}_{3}\right.$ ), 2-octenyl ( $\mathrm{R}=\mathrm{H}_{11} \mathrm{C}_{5}$ ), 3-methyl-2-butenyl ("prenyl", $\mathrm{R}=\mathrm{R}^{\prime}=\mathrm{H}_{3} \mathrm{C}$ ), (E)-3-methyl-2-bexenyl $\left(\mathrm{R}=\mathrm{H}_{7} \mathrm{C}_{3}, \mathrm{R}^{\prime}=\mathrm{H}_{3} \mathrm{C}^{\prime}\right)$ and 3-ethyl-2-pentenyl $\left(\mathrm{R}=\mathrm{R}^{\prime}=\mathrm{H}_{5} \mathrm{C}_{2}\right)$ derivatives.

b) Butenylmagnesium bromide was a $1: 1$ mixture of $(Z)$ - and $(E)$ - stereoisomers while butenylpotassium existed in the $(Z)$-configuration.

c) Although the reagents were always mixed at this temperature, the reaction may have occurred later when the solutions were warmed up.

d) Averaged and rounded off numbers; > 95:5 or < 5:95 means that only trace amounts of a second regioisomer were detected by gas chromatographic analysis.

e) The resulting 2-alkeneboronates were not isolated as such but immediately converted to 2-alken-1-ols by subsequent oxidation with alkaline hydrogen peroxide (ref. 18).

f) Oxirane (ethylene oxide).

\section{SINGLE VS. DOUBLE METALATION OF NON- (HOMO)CONJUGATED DIENES}

Homoconjugated dienes are invariably metalated at the double activated position and thus lead to organometallics of the pentadienyl type (ref. $20-24$ ). The same intermediates (eg. 8) may also be obtained with isomeric 1,3-dienes as the substrates (ref. 22, 25).

\begin{tabular}{|c|c|c|}
\hline & K & \\
\hline $\begin{array}{c}\mathrm{H}_{2} \mathrm{C}=\mathrm{C}-\mathrm{CH}_{2}-\mathrm{CH}_{3}=\mathrm{CH}_{2} \\
\mathrm{H}_{3} \stackrel{\mathrm{C}}{\mathrm{C}} \mathrm{CH}_{3}\end{array}$ & $\begin{array}{c}\mathrm{H}_{2} \mathrm{C}-\mathrm{C}-\mathrm{CH}-\mathrm{C}-\mathrm{CH}_{2} \\
\mathrm{H}_{3} \mathrm{C} \quad \mathrm{CH}_{3}\end{array}$ & $\begin{array}{c}{ }_{2} \mathrm{C}=\mathrm{C}-\mathrm{C}-\mathrm{CH}_{2}=\underset{\mathrm{C}}{\mathrm{C}}-\mathrm{CH}_{3} \\
\mathrm{H}_{3} \mathrm{C}\end{array}$ \\
\hline
\end{tabular}

If, however, the two olefinic double bonds are separated by more than one methylene or methine group only simple allyl- rather than extensively delocalized pentadienylmetal species can be formed. The question now arises under what conditions, if at all, dimetalation can be achieved. With 1,7-octadiene as the model substance the reaction was found to stop cleanly at the monometalation level (9) when tetrahydrofuran served as the solvent. After treatment with methyl iodide $64 \%$ of branched and elongated $C_{9}$ hydrocarbons (in the ratio of $14: 86$ ) and only traces of $\mathrm{C}_{10}$ products were isolated. On the other hand, in hexane exclusive dimetalation (to give 10) took place even when the diene was employed in a 4 fold excess $\left[65 \% \mathrm{C}_{10}\right.$ and virtually no $\mathrm{C}_{9}$ dienes after treatment with methyl iodide (ref. 14)]. A similar medium effect was observed with 1,10-undecadiene. It was found, however, to vanish with higher 1, $\omega$-dienes such as 1,13-tetradecadiene the two allylic sites of which react almost randomly in all solvents (ref. 14). A more subtle medium control had to be devised for 0 -diisopropylbenzene which is very sensitive to polymerization. In neat tetrahydrofuran clean monometalation (to give 11) was achieved while in diethyl ether-rich mixtures almost pure dimetalation product (12) was obtained (ref. 26).

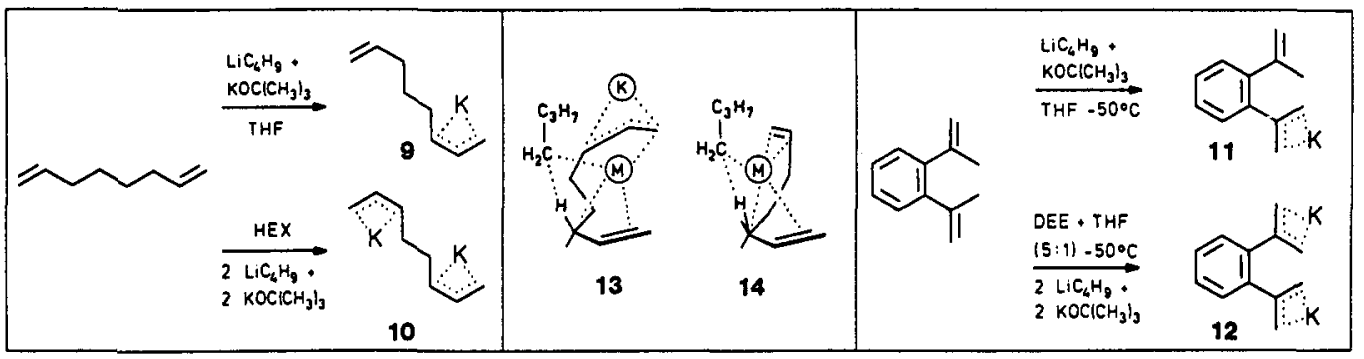


The acceleration of the second metalation with respect to the first one can rationalized by assuming "mixed aggregation" [e.g., transition state 13 (ref. 27)]. It should be also noted that even neighboring double bonds can facilitate the deprotonation of allyl positions : in tetrahydofuran 1,5-hexadiene undergoes monometalation [postulated (ref. 28) transition state 14 (ref. 29)] roughly 5 times faster than does 1,7-octadiene or any terminal alkene (ref. 14).

\section{COMPATIBILITY OF THE SUPERBASE APPROACH WITH FUNCTIONAL GROUPS}

Above $-60^{\circ} \mathrm{C}$, etheral solvents are rapidly attacked by butyllithium in the presence of potassium tert-butoxide. Thus tetrahydrofuran is converted to an $\alpha$-metalated intermediate which, unless trapped, affords ethylene and the potassium enolate of acetaldehyde by fragmentation (ref. 15, 30,31). Nevertheless acetal functions are suitable protection groups for superbase metalations of alkenols as exemplified by 11-methoxymethoxy- and 11-(1-ethoxyethoxy)-1-undecene. Trimethylsilylmethylpotassium (ref. 33), gives better yields of intermediates 15 ( $>70 \%$ ) than butyllithium in the presence of potassium tert-butoxide in such cases (ref. 14).

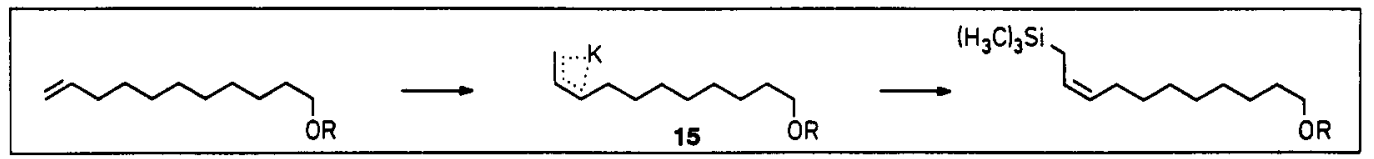

The protection of the hydroxy group can be avoided if 2 equivalents of the superbase mixture are employed in order to form first the corresponding alcoholates (15, OR = OLi or OK). Analogously 3,7-dimethyl-6-octen-1-ol (B-citronellol), 6-methyl-5-hepten-2-ol, 2,6-dimethyl-5-hepten-2-ol and nerol were selectively metalated and the intermediates 16, 17, 18 and 19 trapped as trimethylsilyl derivatives $(38 \%, 56 \%, 37 \%$ and $20 \%$ yield).

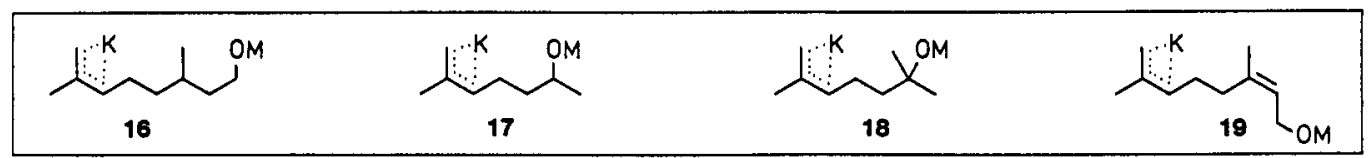

The intermediate 20 obtained by superbase metalation of linalool can be made to undergo a cyclization (ref. 32) already below $25^{\circ} \mathrm{C}$ affording, after intra- or intermolecular proton transfer the cyclopentane intermediate 21 (ref. 14). While metalated 3-methyl-3-buten-1-ol (22) is perfectly stable (ref. 33) the prenol derivative (23) shows some propensity to decompose by metal oxide elimination [under formation of isoprene which polymerizes (ref. 20)]. In the same way unsaturated metal enolates or carboxylates can be submitted to metalation. Thus, 2-methyl-3-butenoic acid after consecutive treatment with 2 equivalents of superbase mixture and chlorotrimethylsilane afforded the derivative 24 with $51 \%$ yield (ref. 14).

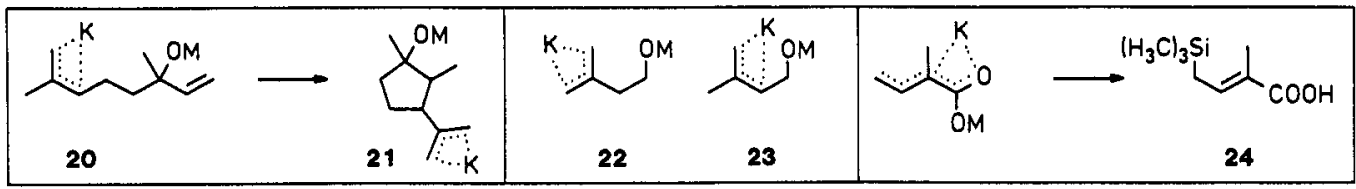

\section{APPLICATION TO A FEW NATURAL PRODUCT SYNTHESES}

Pheromones (ref. 34) not only attract insects but also organic chemists who want to test the performance of a new stereoselective carbon-carbon linking method. Using the cis- or trans-selective modifications (ref. 34) of the Wittig reaction alkenols or the respective esters may be assembled directly at the double bond (ref. 35). Alternatively, a new carbon-carbon bond may be established at the immediately adjacent position by alkylation and subsequent hydrogenation of an acetylene (ref. 36). Modern variants of this classical approach rely on carbocupration (ref. 37), hydroboration (ref. 38) or related techniques. Finally, allyl-type organopotassium reagents of defined endo- or exo-conformation can be connected with carboelectrophiles at a two bonds distance with respect to the location of unsaturation.

$$
\text { via phosphorus ylids }
$$

$$
\begin{aligned}
& \text { vio ocetylenes } \\
& \text { vis }
\end{aligned}
$$

$$
\text { vio allylpotassium intermediates }
$$

The (Z)-9-dodecen-1-ol 25 was obtained as the main product (55\%) after methylation of intermediate 15. Its acetate is the sex attractant of the female grape berry moth Paralobesia viteana (ref. 39). LICKOR metalation of 1-nonene, endo/exo- equilibration and carboxylation affords 3-decenoic acid (26 38\%), the pheromone of virgine furniture carpet beetles Anthrenus flavipes (ref. 40). The conversion of (Z)-2-heptene to the $(Z)-5$-docenyl isovalerate, 27, $\mathrm{OR}=\mathrm{OCOCH}_{2} \mathrm{CH}\left(\mathrm{CH}_{3}\right)_{2}, 31 \%$ ), the pheromone of the Nudaurelia cytherea cytherea moth (ref. 41), involved metalation, addition to oxetane and esterification with the acyl chloride. Monometalation of 
commercial 1,10-undecadiene and subsequent condensation with 3-(2-tetrahydropyranyloxy)propyl iodide leads to $(Z)-5,13$-tetradecadien-1-ol (28, 17\%), a signal substance of Cossus cossus larvae (ref. 42). Regioselective deprotonation of $(Z)-1,12$-heptadecadiene followed by consecutive treatment with formaldehyde and acetic anhydride affords $(3 Z, 13 Z)-3,13$-octadecadienyl acetate 29 , OR $=\mathrm{OCOCH}_{3}, 22 \%$ ), the sex lure of the Sanninoidea exitiosa moth (ref. 43). Carboxylation of the metalated 10-undecen-1-ol (15) and subsequent cyclization (ref. 44 ) gives lactone $30(40 \%)$, a pheromone component of the flat grain beetle Cryptolestes pusillus (ref. 45).

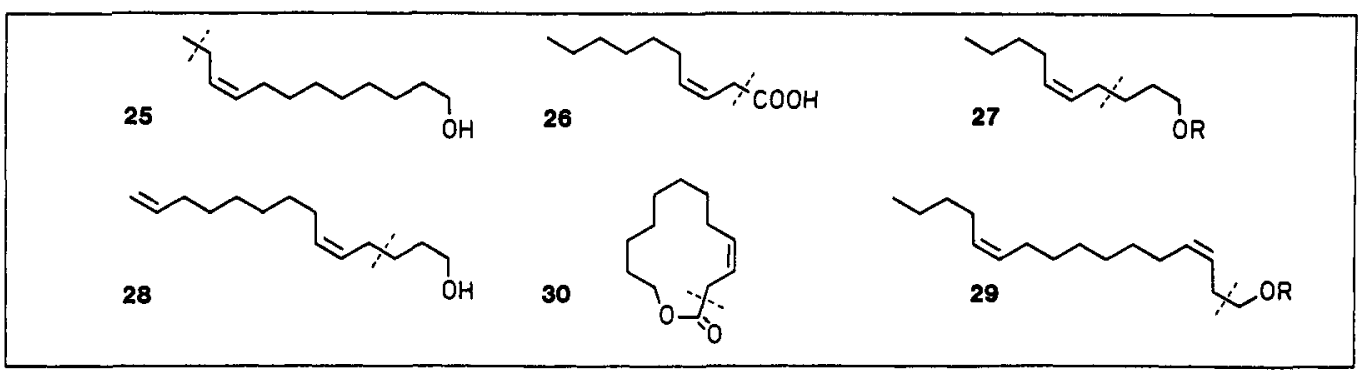

2-Alkenyl boranes and boronates undergo addition to aliphatic or aromatic aldehydes under complete allyl shift and with very high cis $\rightarrow$ threo and trans $\rightarrow$ erythro stereoselectivity (ref. 46). By adapting this method it was possible to synthesize (ref. 47) threo-4-methyl-3-heptanol, the main pheromone component of the elm bark beetle Scolytus multistriatus (ref. 48) as well as the cis-isomer of the oak lactones (quercus lactones, cis-31) starting with cis-2-butene and the trans-isomer (trans-31) starting with $O$-tetrahydropyranyl protected trans-crotyl alcohol (OR $=\mathrm{O}-\mathrm{C}_{5} \mathrm{H}_{10} \mathrm{O}$ ) (ref. 49). When the dimethoxyboryl moiety is replaced by boron having chiral substituents most impressive enantioselectivities can be accomplished in addition to the already known diastereoselectivity (ref. 50).

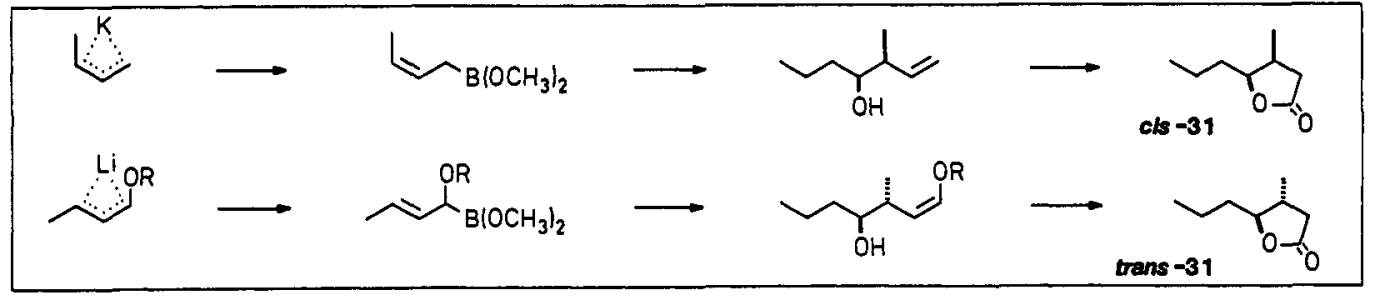

$\alpha$-Terpineol [2-(4-methyl-3-cyclohexenyl)-2-propanol, 1-p-menthen-8-ol] can be transformed to the isomeric perilla alcohol $(32,15 \%)$ by LICKOR metalation, dimethoxyborylation, oxidation, acetylation, pyrolytic elimination of acetic acid and hydrolysis (ref. 14). Consecutive treatment of $(Z)$-1,4-decadiene with sec-butyllithium, fluorodimethoxyboron, hydrogen peroxide and isovaleryl chloride gave $(2 E, 4 Z)$-2,4-decadienyl isovalerate $(33$, $83 \%$ ) which is a constituent of natural cypress oil (ref. 24). Trimethylsilylmethylpotassium is most suitable for metalation of 7,8-dehydrocholesterol; carboxylation occurs at position 7 and produces two diastereomeric acids $34\left[\mathrm{R}=\mathrm{CH}\left(\mathrm{CH}_{3}\right) \mathrm{CH}_{2} \mathrm{CH}_{2} \mathrm{CH}\left(\mathrm{CH}_{3}\right)_{2}, 43 \%\right.$ (ref. 25)]. The LICKOR reagent attacks $\alpha$-terpinene (1-isopropyl-4methyl-1,3-cyclohexadiene) side by side at the allylic methyl group and both methylene positions. The reaction proved however, to be "self-curing" since after the borylation/oxidation sequence anthemol 35 (44\%) was obtained as the only polar substance [besides cymene, $50 \%$ (ref. 23)].

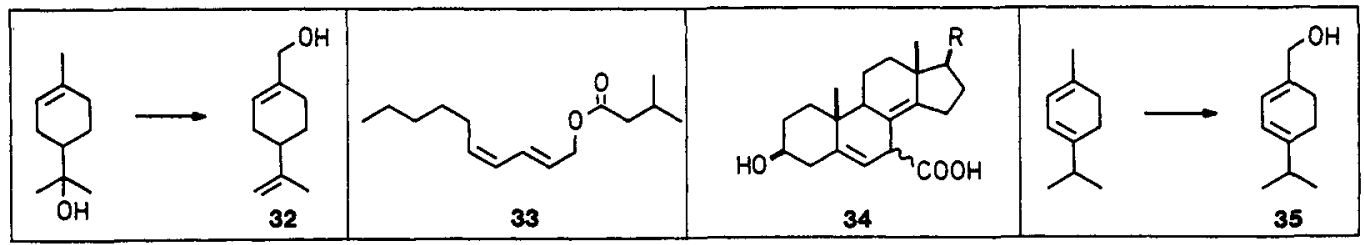

A new access (ref. 50) to vitamin $A$ has been elaborated which uses the same $C_{15}$ and $C_{5}$ building blocks as the BASF process but which is "autostereoselective" by virtue of the intrinsic conformational preferences of the key organometallic intermediate 36. Cleavage of the methyl ether of vinyl $\beta$-ionol with potassium/sodium $(5: 1)$ alloy generated this organopotassium compound of the heptatrienyl type (36). After brief torsional equilibration it had entirely adopted a zigzag band ("triple-V") structure. Thus, upon attachment of an electrophile at the most reactive terminal position the crucial $\Delta^{9}$-double bond inevitably immerged in the desired $(E)$ configuration. The alcohol which is obtained by reaction with $(E)-\beta$-formyl-2-butenyl acetate can be converted to retinol acetate [vitamin A acetate, without optimization 15\% based on vinyl- $\beta$-ionol (ref. 51)].

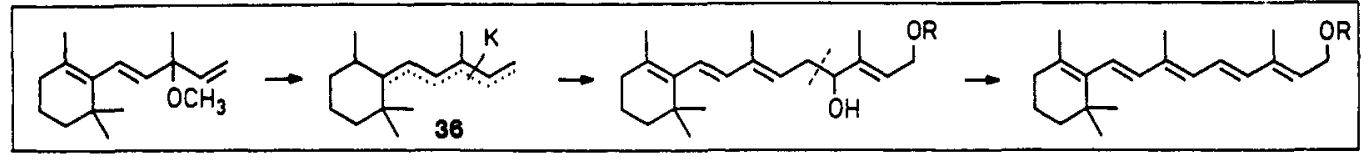




\section{ABOUT THE IDENTITY OF THE SUPERBASIC REAGENT}

Allylsodium becomes a superior catalyst for the polymerization of butadiene when one equivalent of sodium isopropylalcoholate is added (ref. 52). This discovery, made $\mathbf{4 0}$ years ago, stimulated an extensive investigation of organosodium/sodium alcoholate 1:1-mixtures. The alcoholate component was found to accelerate not only polymerization reactions but also Wurtz-type condensations (ref. 53) and the rearrangement of 1,2,2,2-tetraphenylethylsodium (ref. 54). In contrast, the rates of transmetalations between pentylsodium and olefins (ref. 55 56) or alkylbenzenes (ref. 57 - 58) were less unequivocally affected by secondary or tertiary sodium alcoholates. The corresponding potassium alcoholates proved to be more powerful in this respect (ref. 57). Prior to our own work, a single report (ref. 59) drew attention to the specific and exceptionally high reactivity of butyllithium/potassium tert-alcoholate mixtures which were claimed as exceptionally efficient catalysts for the (co)polymerization of dienes and styrenes.

At the beginning the role attributed to the alcoholate was essentially a mechanical one. It was thought to "wrap up" the organosodium reagent (in a monomeric state or as a small aggregate) and thus allow it to display its full reactivity by virtue of an increased solubility (ref. 60). Previously, nmr spectroscopy had revealed a quite similar behavior of lithium alcoholates towards organolithium compounds (ref. 61).

Doubts in a merely "peptizing" (ref. 60) action of alcoholates arouse when Lim and associates discovered an unprecedented kind of metal/metal exchange. By simply stirring a suspension of sodium tert-butoxide in a solution of butyllithium in hexane they obtained almost pure butylsodium (ref. 62). A similar experiment with potassium tert-butoxide gave less conclusive results. Later, however, the Czechoslowakian polymer chemists elaborated modified procedures which assured almost complete conversion of butyllithium to butylpotassium too (ref. 63). The outcome of such remarkable metal/metal repartitioning, however, has no direct bearing on the nature of the superbasic species which under in situ conditions promote an irreversible transmetalation reaction. Thus, it is unwarranted to consider the LICKOR reagent as nothing else but butylpotassium.

Butylpotassium is known since half a century (ref. 64) and it can be prepared very easily (ref. 64, 65). With 1 alkenes it reacts under concomitant attack at olefinic and allylic positions (ref. 66 ) while the LICKOR mixture gives the virtually pure allylmetal intermediates with excellent yields. The non-identity of the two reagents is further corroborated by unambiguous differences in the regioselectivity of cumene metalation [deprotonation of aromatic is benzylic and meta us para positions (ref. 67)], in kinetic $k_{\mathrm{H}} / k_{\mathrm{D}}$ isotope effects of benzene or toluene metalation (ref. 68) and in the stability towards tetrahydrofuran (ref. 30). Actually, the finding that the LICKOR components can be dissolved and kept in this medium at temperatures around or below $-60^{\circ} \mathrm{C}$ was of greatest practical importance since it encouraged us to carry out metalations more and more frequently in homogeneous medium rather than in hexane slurries.

So far all evidence confirms our view (ref. 5) that the true superbasic reagent is an organometal/alcoholate aggregate which is fairly long-lived in cold tetrahydrofuran while it progressively disproportionates in paraffinic media. As long as detailed spectroscopic and kinetic data are lacking it is difficult to decide whether the LICKOR reagent is a $1: 1$ adduct or a $1: n$ (e.g., $1: 3)$ adduct if not a higher aggregate (e.g., $2: 2$ adduct) or an ate complex (ref. 67), to mention just a few possibilities. Unfortunately, we were unable to record ${ }^{13} \mathrm{C}$-nmr spectra of butylpotassium in neat tetrahydrofuran although we succeeded with methylpotassium $[\delta-2.10 \mathrm{ppm}]$ and with trimethylsilylmethylpotassium [ $\delta-1.14 \mathrm{ppm}]$ (ref. 69). This failure prompted us first to explore the mechanistic pecularities of less labile organometallic intermediates (ref. 70). Thus, benzylpotassium was found to undergo rapid transmetalation with 2-methylnaphthalene until equilibrium between the two $\mathrm{CH}$-acids involved and the corresponding potassium "bases" was reached. Benzyllithium proved to be considerably less reactive.
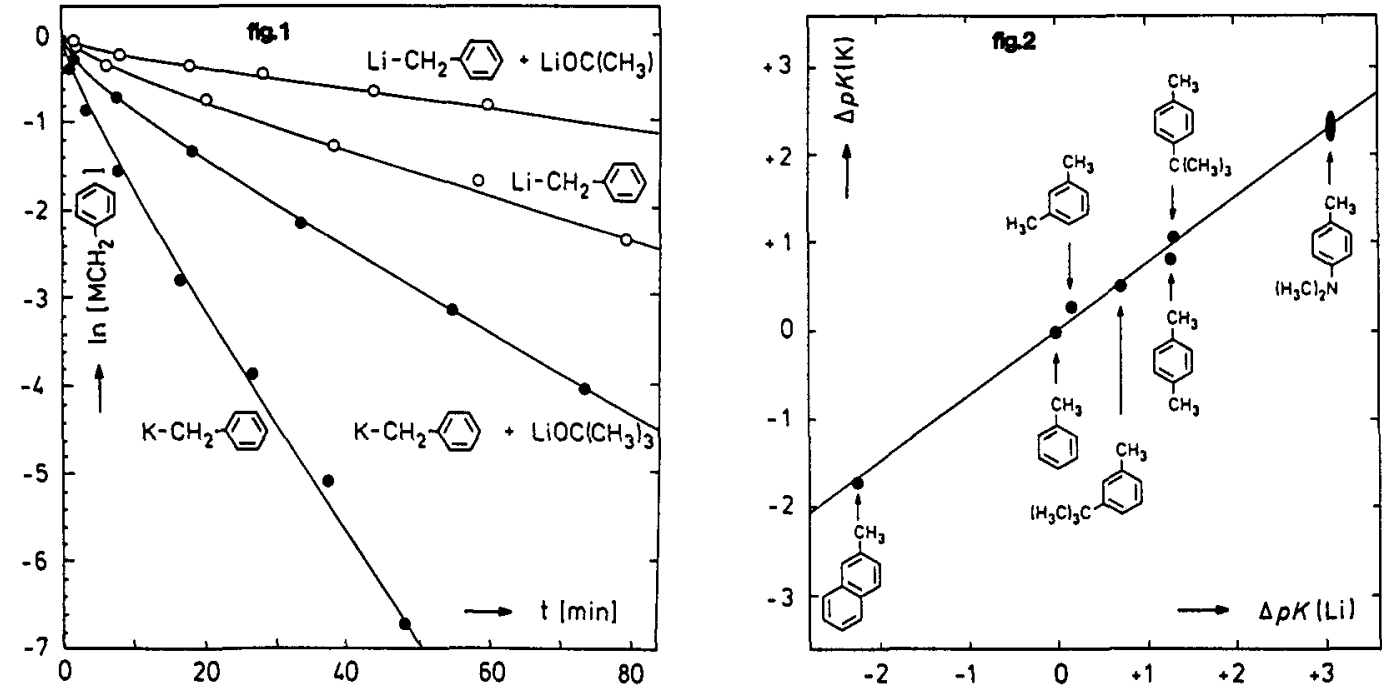
Addition of lithium tert-butoxide caused a retardation of both reactions (see figure 1). The metals did not only affect the rate with which an acid/base equilibrium was established but also the position to which it was shifted. The intrinsic $\mathrm{CH}$-acidities of seven substrates, all belonging to the toluene family, were pairwise compared in transmetalation reactions. The potassium compounds gave a stronger response, i.e. a steeper slope, than the lithium series (see figure 2).

In the context of this investigation we also examined the chemical stability of solutions of benzylpotassium in tetrahydrofuran at $25^{\circ} \mathrm{C}$. They turned out to be very capricious : after a long, though variable incubation period, during which nothing happened, suddenly a very fast decomposition of the reagent started. In contrast, mixtures of benzyllithium and potassium tert-butoxide or benzylpotassium and lithium tert-butoxide were found to be almost indefinitely stable. This observation may provide a clue to the understanding of what is so special about the LICKOR reagent. Although its reactivity potential is somewhat diminished when compared with butylpotassium, the mixed aggregate appears to be much better protected against uncontrolled side reactions and autodestruction.

Acknowledgements The author wishes to thank his highly motivated and talented coworkers, notably Herbert Bosshardt, Olivier Desponds, Jürgen Hartmann, Ruth Lehmann, Christian Margot, Etienne Moret, Günter Rauchschwalbe and Manfred Stähle, for their efforts and he is indebted to the Schweizerische Nationalfonds zur Förderung der wissenschaftlichen Forschung, Bern, for financial support.

\section{REFERENCES}

[1] Reviews : M. Schlosser, Angew. Chem. 76 (1964), 124, 258; Angew. Chem. Int. Ed. Engl. 3 (1964), 287, 362; H.F. Ebel in Houben Weyl : Methoden der organischen Chemie (editor : E. Müller), vol. 13/1, 261, G. Thieme Verlag, Stuttgart 1970; M. Schlosser, Struktur und Reaktivität polarer Organometalle, Springer Verlag, Berlin 1973.

[ 2] G.G. Eberhardt, W.A. Butte, J. Org. Chem. 29 (1964), 2928.

[3] J. Klein, A. Medlik, J. Chem. Soc., Chem. Commun. 1973, 275; S. Akiyama, J. Hooz, Tetrahedron Lett. 14 (1973), 4115.

[ 4] R.B. Bates, W.A. Beavers, J. Am. Chem. Soc. 96 (1974), 5001.

[5] M. Schlosser, J. Organomet. Chem. 8 (1967), 9.

[6] M. Schlosser, J. Hartmann, Angew. Chem. 85 (1973), 544; Angew. Chem. Int. Ed. Engl. 12 (1973), 439; Angew. Chem. 86 (1974), 751; Angew. Chem. Int. Ed. Engl. 13 (1974), 701.

[7] P.D. Bartlett, S. Friedman, M. Stiles, J. Am. Chem. Soc. 75 (1953), 1771.

[ 8] M. Stähle, J. Hartmann, M. Schlosser, Helv. Chim. Acta 60 (1977), 1730.

[ 9$]$ G.M. Whitesides, J.E. Nordlander, J.D. Roberts, J. Am. Chem. Soc. 84 (1962), 2010.

[10] M. Schlosser, M. Stähle, Angew. Chem. 92 (1980), 497; Angew. Chem. Int. Ed. Engl. 19 (1980), 487; M. Stähle, M. Schlosser, J. Onganomet. Chem. 220 (1981), 277.

[11] See also S. Brownstein, S. Bywater, D.J. Worsfold, J. Organomet. Chem. 199 (1980), 1.

[12] The low-temperature crystal structure of the monomeric allyllithium $/ N, N, N, N^{\prime \prime}, N^{\prime \prime}$-pentamethyldiethylenetriamine complex does indeed reveal an asymmetric bridging of the allyl moiety by the metal [U. Schümann, E. Weiss, H. Dietrich, W. Mahdi, J. Organomet. Chem. 322 (1987), 299]. Actually we suppose alkali metal compounds of the allyl-type to exist predominantly as monomers in tetrahydrofuran solution (ref. 10).

[13] J.E. Nordlander, W.G. Young, J.D. Roberts, J. Am. Chem. Soc. 83 (1961), 494; P. West, J.I. Purmort, S.V. McKinley, J. Am. Chem. Soc. 90 (1968), 797; see also : T.B. Thompson, W.T. Ford, J. Am. Chem. Soc. 101 (1979), 5459; R.T. McDonald, S. Bywater, Organometallics 5 (1986), 1529.

[14] E. Moret, doctoral dissertation, Lausanne University, 1980.

[15] E. Moret, unpublished results (1987).

[16] E. Moret, J. Fürrer, M. Schlosser, Tetrahedron 44 (1988), 3539.

[17] M. Schlosser, J. Hartmann, J. Am. Chem. Soc. 98 (1976), 4674.

[18] G. Rauchschwalbe, M. Schlosser, Helv. Chim. Acta 58 (1975), 1094.

[19] E. Moret, K. Fujita, C. Margot, K. Koch, unpublished results (1977 - 1988).

[20] J. Hartmann, R. Muthukrishnan, M. Schlosser, Helv. Chim. Acta 57 (1974), 2261.

[21] R.B. Bates, D.W. Gosselink, J.A. Kaczynski, Tetrahedron Lett. 8 (1967), 199, 205; G.J. Heiszwolf, H. Kloosterziel, Recl. Trav. Chim. Pays-Bas 86 (1967), 807; H. Kloosterziel, J.A.A. van Drunen, Recl. Trav. Chim. Pays-Bas 89 (1970), 270; W.T. Ford, M. Newcomb, J. Am. Chem. Soc. 96 (1974), 309.

[22] M. Schlosser, G. Rauchschwalbe, J. Am. Chem. Soc. 100 (1978), 3258.

[23] M. Schlosser, H. Bosshardt, A. Walde, M. Stähle, Angew. Chem. 92 (1980), 302; Angew. Chem. Int. Ed. Engl. 19 (1980), 303.

[24] H. Bosshardt, M. Schlosser, Helv. Chim. Acta 63 (1980), 2393.

[25] E. Moret, M. Schlosser, Tetrahedron Lett. 25 (1984), 1449.

[26] O. Desponds, unpublished results (1988).

[27] Other examples, M. Schlosser, Struktur und Reaktivität polarer Organometalle, Springer Verlag, Berlin, 1973, p. $137-138$.

[28] For an alternative explanation see : M. Stähle, R. Lehmann, J. Kramar, M. Schlosser, Chimia 39 (1985), 229; A. Mordini, M. Schlosser, Chimia 40 (1986), 309.

[29] Dimetalation of 1,5-hexadiene : R.B. Bates, W.A. Beavers, M.G. Greene, J.H. Klein, J. Am. Chem. Soc. 96 (1974), 5640; see also : S.K. Arora, R.B. Bates, W.A. Beavers, R.S. Cutler, J. Am. Chem. Soc. 97 (1975), 6271 .

[30] R. Lehmann, M. Schlosser, Tetrahedron Lett. 25 (1984), 745.

[31] By the way, the superbase also metalates $N, N, N^{\prime}, N^{\prime}$-tetramethylethyleneamine (yields of derivatives up to $45 \%$, L. Rothen, diploma work, Université de Lausanne, 1985, and unpublished results). See also D.J. Peterson, J. Organomet. Chem. 21 (1970), P63; W.N. Smith, Adv. Chem. Ser. 130 (1974), 23 (American Chemical Society, Washington); H. Ahlbrecht, H. Dollinger, Tetrahedron Lett. 25 (1984), 1353. 
[32] See also : R.C. Lamb, P.W. Ayers, M.C. Toney, J. Org. Chem. 27 (1962), 1441; M.E. Howden, A. Maercker, J. Burdon, J.D. Roberts, J. Am. Chem. Soc. 88 (1966), 1732; J.F. Garst, P.W. Ayers, R.C. Lamb, J. Am. Chem. Soc. 88 (1966), 4261; H.G. Richey, T.C. Rees, Tetrahedron Lett. 7 (1966), 4297; E.A. Hill, R.J. Theissen, A. Doughty, R. Miller, J. Org. Chem. 34 (1969), 3681; H. Felkin, L.D. Kwart, G. Swierczewski, J.D. Umpleby, J. Chem. Soc., Chem. Commun. 1975, 242; J.H. Edwards, F.J. Mcquillin, J. Chem. Soc., Chem. Commun. 1977, 838; W. Oppolzer, P. Schneider, Helv. Chim. Acta 69 (1986), 1817.

[33] R.M. Carlson, L.L. White, Synth. Commun. 13 (1983), 237.

[34] Reviews : C.A. Henrick, Tetrahedron 33 (1977), 1845; R. Rossi, Synth. Commun. 1977, 817; 1978, 413; J.M. Brand, J.C. Young, R.M. Silverstein, Fortschritte der Chemie organischer Naturstoffe (Progress in the Chemistry of Natural Products), 37 (1979), 1, Springer Verlag, Wien.

[35] M. Schlosser, K.F. Christmann, Angew. Chem. 78 (1966), 115; Angew. Chem. Int. Ed. Engl. 5 (1966), 126; M. Schlosser, G. Müller, K.F. Christmann, Angew. Chem. 78 (1966), 677; Angew. Chem. Int. Ed. Engl. 5 (1966), 667; M. Schlosser, Topics Stereochem. 5 (1970), 1.

[36] A.M. Moiseenkov, B. Schaub, C. Margot, M. Schlosser, Tetrahedron Lett. 26 (1985), 305; B. Schaub, G. Blaser, M. Schlosser, Tetrahedron Lett. 26 (1985), 307; M. Schlosser, Huynh Ba Tuong, B. Schaub, Tetrahedron Lett. 26 (1985), 311; see also : H.J. Bestmann, J. Süß, O. Vostrowsky, Liebigs. Ann. Chem. $1981,2117$.

[37] A. Alexakis, G. Cahiez, J.F. Normant, Synthesis 1979, 826; N. Jabri, A. Alexakis, J.F. Normant, Tetrahedron Lett. 22 (1981), 959; 23 (1982), 1589; M. Gardette, N. Jabri, A. Alexakis, J.F. Normant, Tetrahedron 40 (1984), 2741; M. Furber, R.J.K. Taylor, S.C. Burford, Tetrahedron Lett. 27 (1985), 3285.

[38] N. Miyaura, H. Suginome, A. Suzuki, Tetrahedron Lett. 24 (1983), 1527; G. Cassani, P. Massardo, P. Piccardi, Tetrahedron Lett. 24 (1983), 2513; N. Miyaura, K. Yamada, H. Suginome, A. Suzuki, J. Am. Chem. Soc. 107 (1985), 972; N. Miyaura, M. Satoh, A. Suzuki, Tetrahedron Lett. 27 (1986), 3745; F. Björkling, T. Norin, C.R. Unelius, R.B. Miller, J. Org. Chem. 52 (1987), 292; H.C. Brown, D. Basavaiah, S.M. Singh, N.G. Bhat, J. Org. Chem. 53 (1988), 246.

[39] W.L. Roelofs, J.P. Tette, E.F. Taschenberg, A. Comeau, J. Insect Physiol. 17 (1971), 2235; Chem. Abstr. 76 (1972), 56'324v.

[40] H. Fukui, F. Matsumura, M.C. Ma, W.G. Burkholder, Tetrahedron Lett. 15 (1974), 3563.

[41] H.E. Henderson, F.L. Warren, O.P.H. Augustyn, B.V. Burger, D.F. Schneider, P.R. Boshoff, H.S.C. Spies, H. Geertsema, J. Chem. Soc., Chem. Commun. 1972, 686.

[42] L. Garanti, A. Marchesin, U.M. Pagnoni, R. Trave, Gazz. Chim. Ital. 106 (1976), 187; Chem. Abstr. 77 (1976), 5'620b.

[43] J.H. Tumlinson, C.E. Yonce, R.E. Doolittle, R.R. Heath, C.R. Gentry, E.R. Mitchell, Science 185 (1974), 614; Chem. Abstr. 81 (1974), 117326z.

[44] J.G. Millar, A.C. Oehlschlager, J.W. Wong, J. Org. Chem. 48 (1983), 4404.

[45] J.G. Millar, H.D. Pierce, A.M. Pierce, A.C. Oehlschlager, J.H. Borden, A.V. Barak, J. Chem. Ecol. 11 (1985), 1053; Chem. Abstr. 103 (1985), 193'344s.

[46] B.M. Mikhailov, Organomet. Chem. Rev. A8 (1972), 1.

[47] M. Schlosser, K. Fujita, Angew. Chem. 94 (1982), 320; Angew. Chem. Int. Ed. Engl. 21 (1982), 309; Angew. Chem. Suppl. 1982, 646 - 653.

[48] K. Mori, Tetrahedron 33 (1977), 289.

[49] E. Moret, M. Schlosser, Tetrahedron Lett. 25 (1984), 4491; for a related approach see : D. Hoppe, A. Brönnecke, Tetrahedron Lett. 24 (1983), 1687; D. Hoppe, Angew. Chem. 96 (1984), 930; Angew. Chem. Int. Ed. Engl. 23 (1984), 932.

[50] H.C. Brown, K.S. Bhat, J. Am. Chem. Soc. 108 (1986), 293; W.R. Roush, R.L. Haltermann, J. Am. Chem. Soc. 108 (1986), 294; see also : R.W. Hoffmann, W. Ladner, K. Steinbach, W. Masses, R. Schmidt, G. Snatzke, Chem. Ber. 114 (1981), 2786; M.M. Midland, S.B. Preston, J. Am. Chem. Soc. 104 (1982), 2330; M.T. Reetz, Pure Appl. Chem. in press (7th IUPAC Conference on Organic Synthesis, Nancy, 4 - 7 July 1988).

[51] G. Rauchschwalbe, unpublished results (1976).

[52] A.A. Morton, E.E. Magat, R.L. Letsinger, J. Am. Chem. Soc. 69 (1947), 950.

[53] A.A. Morton, A.E. Brachman, J. Am. Chem. Soc. 73 (1951), 4363.

[54] T.F. Crimmins, W.S. Murphy, C.R. Hauser, J. Org. Chem. 31 (1966), 4273.

[55] A.A. Morton, M.E.T. Holden, J. Am. Chem. Soc. 69 (1947), 1675.

[56] A.A. Morton, F.D. Marsh, R.D. Coombs, A.L. Lyons, S.E. Penner, H.E. Ramsden, V.B. Baker, E.L. Little, R.L. Letsinger, J. Am. Chem. Soc. 72 (1950), 3785.

[57] A.A. Morton, C.E. Claff, F.W. Collins, J. Org. Chem. 20 (1955), 428.

[58] A.A. Morton, J.L. Eisenmann, J. Org. Chem. 23 (1958), 1469.

[59] Brit. Pat. 1'029'445 to Phillips Petroleum Co. (filed 6 November 1964).

[60] R.L. Benkeser, T.F. Crimmins, Wen-hong Tong, J. Am. Chem. Soc. 90 (1968), 4366.

[61] T.L. Brown, J.A. Ladd, G.N. Newman, J. Organomet. Chem. 3 (1965), 1; T.L. Brown, Acc. Chem. Res. 1 (1968), 23; see also : L. Lochmann, J. Pospisil, J. Vodnansky, J. Trekoval, D. Lím, Coll. Czech. Chem. Commun 30 (1965), 2187.

[62] L. Lochmann, J. Pospisil, D. Lím, Tetrahedron Lett. 7 (1966), 257.

[63] L. Lochmann, D. Lím, J. Organomet. Chem. 28 (1971), 153; L. Lochmann, J. Trekoval, J. Organomet. Chem. 326 (1987), 1; L. Lochmann, Coll. Czech. Chem. Commun. 52 (1987), 2710; L. Lochmann, J. Trekoval, Coll. Czech. Chem. Commun.53 (1988), 76.

[64] H. Gilman, J.C. Bailie, J. Org. Chem. 2 (1937), 84.

[65] D. Bryce-Smith, E.E. Turner, J. Chem. Soc. 1953, 861; D. Bryce-Smith, J. Chem. Soc. 1963, 5983.

[66] C.D. Broaddus, T.J. Logan, T.J. Flautt, J. Org. Chem. 28 (1963), 1174; C.D. Broaddus, J. Org. Chem. 29 (1964), 2689.

[67] M. Schlosser, S. Strunk, Tetrahedron Lett. 25 (1984), 741.

[68] J.H. Choi, M. Schlosser, unpublished results (1987 - 1988).

[69] R. Lehmann, T. Jenny, M. Schlosser, unpublished results (1985).

[70] E. Moret, O. Desponds, M. Schlosser, unpublished results (1987 - 1988). 